\title{
Immunogenicity Specimen Assessments Lower Limit of Quantitation
}

National Cancer Institute

\section{Source}

National Cancer Institute. Immunogenicity Specimen Assessments Lower Limit of

Quantitation. NCI Thesaurus. Code C117570.

The lowest value in a possible range of values for the immunogenicity specimen assessment. 